\title{
POSTHUMANITY IN DELILLO'S ZERO K: THE RISING CONNECTIONS BETWEEN IDENTITY AND TECHNOLOGY
}

\author{
Alan Medeiros Casteluber ${ }^{1^{*}}$ \\ Giséle Manganelli Fernandes ${ }^{1^{* *}}$ \\ ${ }^{1}$ Universidade Estadual Paulista, São José do Rio Preto, SP, Brasil
}

\begin{abstract}
In Zero $K$, DeLillo revisits the ever-increasing connection between identity and technology. However, he does so in a unique way, adding (im) mortality issues to an already complex mix. As a result, DeLillo not only explores the intricacies of our present context, but also provides a bleak picture of what could be our posthuman future. This paper examines how DeLillo's fiction reveals subjectivity in our current post-modern society. The focus of this investigation gravitates specifically to the interference of a technological influx that overtakes contemporary life. It analyzes the process by which our interdependence in machines, electronic devices, and its systems has made them an extension of our own body. Pushing the boundaries of this relationship to an extreme, the book explores the distorted view of technology as "another God", but, unlike the other gods, it actually "delivers" salvation.

Keywords: technology; subjectivity; posthuman; DeLillo; Zero K
\end{abstract}

\footnotetext{
Ph.D. Candidate in Languages at the "Júlio de Mesquita Filho" São Paulo State University (UNESP) in São José do Rio Preto-SP. MA in Languages by the Federal University of Viçosa. This author conducts research in the field of Foreign Literature. E-mail address: alanmcasteluber@gmail.com. ORCID: https://orcid.org/00000001-6304-6354.

** Associate Professor II at the Department of Modern Languages at UNESP / São José do Rio Preto. This author holds BA in Languages from USP, an MA in Literature from UNESP and a PhD in Linguistic and Literary Studies in English from USP. The author has also completed a postdoctoral fellowship funded by FAPESP at the University of Florida (USA). "O Pós-Modernismo" (Teoria literária: abordagens históricas e tendências contemporâneas, 4th edition, 2019) and "De vozes outrora silenciadas ao poder de reelaboração do eu" (Línguas em trânsito na literatura: espaços, memórias, identidades, 2019) are among the author's most recent publications. E-mail address: gisele.manganelli-fernandes@unesp.br. ORCID: https://orcid.org/0000-0002-
} 4194-3414. 
The ever-increasing influence that technology has on daily life and on subjectivity stands as a recurrent theme in Don DeLillo's fiction. In White Noise (1985), the author portrays the television and radio almost as characters in their own right, their mechanical "voices" directly altering perception and beliefs of human subjects with a constant stream of sounds and images. In Cosmopolis (2003), Eric Packer's highly advanced limousine functions as his private and empowering micro-universe, allowing him to perform various activities - from having medical appointments to destabilizing global markets - without ever having to leave it. Even in essays such as "The Power of History" (1997), the author does not spare comments about how technology is an important feature of contemporary culture, deeply altering people's lives and their perception of time:

The microwave, the VCR remote, the telephone redial button and other time-collapsing devices may make us feel that our ordinary household technology reflects something that flows through the deep mind of the culture, an impatient craving for time to move faster. (DeLillo 62)

The examples are numerous and several novels from DeLillo have had the effects of technology expansion weaved into their narratives in some way or another.

Zero K (2016), DeLillo's most recently published science fiction novel, is no different. The author revisits this subject, but does so in a unique way. Through the ideals of the Convergence, Zero K's main setting, the writer explores the distorted view of technology as "another God, [...] - real, true" (8), and which, unlike other gods, "delivers" salvation.

Zero $K$ narrates the story of Jeff Lockhart, who is called to say goodbye to his dying stepmother, Artis. His father Ross Lockhart, Artis' husband, finds motivation in this upcoming loss to become one of the main investors of the cryonic facility called The Convergence. In the compound, billionaires give their lives prematurely in order to be kept in cryopreservation, until a future time, hoping that new technologies and advances in medicine become capable of improving their bodies, eventually culminating in their reanimation or resuscitation.

While one of the facility's purposes is to freeze decaying and failing human bodies like Artis', it is also built in preparation for the apocalypse they believe to be imminent - a belief that comes with a myriad of consequences to be discussed here. As the narrative advances, we discover that Artis is scheduled to undergo the procedure in a few days. We follow the protagonist and narrator Jeff through the halls of the Convergence, rejecting the whole enterprise of the facility, despite Ross' arguments in favor of it. Father and son's frail relationship dynamic is further complicated when Ross, whose health is not at risk, also decides to join Artis in this venture to the cryonic pod, both because of his grief, but also because of his immense faith in the feasibility of the process, and his full conviction that this remarkable technology constitutes the only path to a new world and a new form of transcendence. 
By adding (im)mortality issues to an already complex mix, DeLillo pushes the boundaries of our relationship with technology to an extreme, creating a universe that not only explores the intricacies of our present context, but also provides a bleak picture of what could be our posthuman future.

Speaking of the posthuman and posthumanism is always a tricky endeavor, as these terms are conceptualized and used in widely different ways. First and foremost, from a philosophical stance, posthumanism "is 'post' to the concept of the human and to the historical occurrence of humanism, both based [...] on hierarchical social constructs and human-centric assumptions." (Ferrando 29) It poses an inquiry into anthropocentric and humanistic beliefs, questioning the emphasis on human value and the existence of an intrinsic human nature. Posthumanism also directly opposes humanism's idea of an autonomous and unified subject, rational and capable of free will.

It is arguable that the posthuman owes its origins to Donna Haraway's "A Cyborg Manifesto" (2016), in which the critic uses the myth of the cyborg to (re) conceptualize the contemporary subject and its relations with the world. The cyborg is a "cybernetic organism", a hybrid, simultaneously animal and machine (Haraway 5). The myth of the cyborg is extracted from both contemporary science fiction and modern use of technology, particularly medicine. As such, "[t] he cyborg is a condensed image of both imagination and material reality" (Haraway 7).

For Haraway, the cyborg is characterized by "transgressed boundaries" and "potent fusions" between animal, human and machine (14). The critic points out that, by the late twentieth century, several of these boundaries began to be breached, in a way that made it difficult to set humans apart from several traditionally non-human elements. Regarding the animal-human boundary, all aspects that were once understood as unique to human beings, such as "language, tool use, social behavior, mental events", simply no longer apply, so that "nothing really convincingly settles the separation of human and animal" (Haraway 10). This shift in perspective will contribute to the upcoming review of the human as the apex of existence that will be discussed further.

As modern technology development continues to advance at unprecedented speed, the second boundary, between human and machine, gets increasingly thin, so much so that the latest machines

[...] have made thoroughly ambiguous the difference between natural and artificial, mind and body, self-developing and externally designed, and many other distinctions that used to apply to organisms and machines. Our machines are disturbingly lively, and we ourselves frighteningly inert. (Haraway 11).

In short, Haraway affirms that we live in a "mythic time" in which we are all cyborgs - "chimeras, theorized and fabricated hybrids of machine and organism" (7).

Some readings have taken Haraway's text literally, that is, an accelerated relationship and eventual fusion of human and technology. Although these readings are increasingly relevant in the present context, this was not necessarily 
the focus of her writing. The feminist critic portrays the cyborg as a "creature in a postgender world", "in partial connection with others, in communication with all of our parts" (Haraway 8, 67). Drawing upon the myth of the cyborg, a being made of several different parts arranged together, the writer discusses subjectivity itself in these terms. Much like posthumanism will do later, Haraway opposes the humanist subject and its "myth of original unity", proposing subjectivity as being "resolutely committed to partiality" $(8,9)$. Therefore, both Haraway's cyborg and the posthuman subject recognize disunity within oneself as well as fluid and distinct identities coexisting in one body.

Having discussed its origins, posthumanism, as mentioned earlier, "has become an umbrella term" (Ferrando 29) that includes numerous different perspectives. In this article, we will explore the subject under numerous frameworks developed by different writers. It shall be stated here that the selection of these critics is not because they do not differ in any way - they do. However, we will focus on what each of these perspectives adds and offers to the interpretation of Zero K.

Posthumanism, as we reviewed, inherits many of the concepts formulated by Haraway. Starting from the celebration of the death of the humanist subject, posthumanism can be seen as an "overcoming of human primacy" (Ferrando 29). It is a post-exclusivist philosophy that offers a way back for humans to reconnect with the non-human universe - "a reconciliation of existence in its broadest significations", as stated by Ferrando (29). Along the same line, Robert Peperell (2003) affirms that posthumanism is about how we choose to live, how we investigate the other as well as our own assumptions, but most importantly how we choose to conduct the continuous "exploitation of the environment, animals and each other" (171). For the critic, evidence of the end of humanism is obvious in manifestations "that resist the worst aspects of humanist behavior" (Pepperell 171): feminism, animal rights, environmentalism, and anti-slavery - all of these are movements that resist some form of human exploitation. Furthermore:

The very existence of such movements over the last 200 years or so suggests the gradual overturning of a human-centred world is well underway. More importantly, the recognition that none of us are actually distinct from each other, or the world, will profoundly affect the way we treat each other, different species and the environment. (Pepperell 172).

It should be clear, by now, why the debate on the posthuman has become a pressing concern. It is no coincidence that more and more "explorations into the posthuman and posthumanism have emerged" in recent years (Costa; Cavalcanti; Haran 9). They have come "as a response to the current economic, political, cultural, and ecological crises affecting us all" (Costa; Cavalcanti; Haran 9), in short - to the disastrous consequences of unchecked human actions on Earth.

In How we Became Posthuman (1999), Katherine Hayles too tries to craft a concept of the posthuman "that will be conducive to the long-range survival of humans and of the other life-forms, biological and artificial, with whom we share the planet and ourselves" (291). Nevertheless, the author recognizes that "some 
current versions of the posthuman point toward the antihuman and the apocalyptic" (Hayles 291). Despite the aforementioned efforts put into the reconciliation of existence between human and non-human, it is becoming increasingly clear for some that we, simply put, are destroying the world beyond reparation.

This somber interpretation is the one that conducts Glavanakova's (2017) exploration of Zero $K$. The author states that "[ $t]$ he alternative reading of the posthuman that is the relevant one in the discussion of DeLillo's text is related to the fear of immanent disaster, the catastrophic event just waiting to happen" (Glavanakova 101).

Her work refers to numerous critical texts that hold the "shared belief that we live on the verge of an extinction event to take place within the next 240-540 years, according to scientific projections" (Barnosky et al. 55, apud. Glavanakova 92).

The same belief, as we have previously mentioned, is also shared by the characters responsible for the creation of the Convergence facility in Zero K's universe. DeLillo, thus, utilizing both the elements from science fiction and the increasingly real signs of a possible extinction event, crafts a contemplative text, one that "causes an apocalyptic anxiety to run through [its] pages [...] and through the minds of his characters and of his readers" (Glavanakova 95).

Although this article also deals with the apocalyptic scenario, there is also another matter that will guide the central focus of our discussion. At its very core, posthumanism also examines the intimate relationship between humans and technology, much like some readings of Haraway's cyborg theory have done before. As Pepperell affirms, the posthuman is also "about the evolution of life, a process not limited to genetics, but which includes all the paraphernalia of cultural and technological existence" (171). In this line of thought, the focus of our investigation on the "cybernetic posthuman" gravitates specifically to the interference of a technological influx that overtakes contemporary life. It analyzes the process by which our interdependence in machines, electronic devices, and its systems has made them an extension of our own body.

It is here that we return to Hayles's research of information technologies in How we Became Posthuman (1999) in a more in-depth way. The writer points out how certain conceptualizations in this field not only allow, but actively encourage, some aspects of the humanist subject to continue surviving - more specifically, the hierarchic separation of mind and body.

Regarding the humanist subject, the critic explains how this hierarchic separation was vital to humanism's agenda in the following:

Identified with the rational mind, the liberal subject possessed a body but was not usually represented as being a body. Only because the body is not identified with the self is it possible to claim for the liberal subject its notorious universality, a claim that depends on erasing markers of bodily difference, including sex, race, and ethnicity. (Hayles 4, 5).

On the other hand, in the realm of the "cybernetic construction of the posthuman", "embodiment has been systematically downplayed or erased [...] 
in ways that have not occurred in other critiques of the liberal humanist subject, especially in feminist and postcolonial theories" (Hayles 4).

In order to explain her argument, the critic turns to the origins of her research. It started when reading Moravec's (1988) Mind Children: The Future of Robot and Human Intelligence and his argument that "it will soon be possible to download human consciousness into a computer" (Hayles 1). Manifesting her incredulity on how it was possible for "someone of Moravec's obvious intelligence to believe that mind could be separated from body", Hayles was also "[s]hocked into awareness" by discovering "he was far from alone" in those beliefs (1).

Therefore, Katherine Hayles undergoes a research odyssey in the history of cybernetics, and in the history of cultural and literary texts concerned with information technologies in order to investigate this conjecture. She discovers many interrelated stories that reveal how human consciousness came to be conceptualized in some fields and theories purely as an informational pattern, leading to the erasure of embodiment. In this conceptualization, information is separated from materiality as distinct entities. According to the critic, this "allows the construction of a hierarchy in which information is given the dominant position and materiality runs a distant second" (Hayles 12). Our bodies are perceived, thus, as accessories. It poses that embodiment has no bearing on human consciousness, and the body we are born with is just one of the many possible mediums.

As such, the author concludes that posthumanism continues this specific humanist tradition "rather than disrupts it" (Hayles 5). For both the humanist subject and the cybernetic posthuman, the body is just a repository for the mind, that is, embodiment is treated as "the instantiation of thought/ information" (Hayles 5).

Considering all of the above, we will argue, in this article, that the novel at hand, DeLillo's Zero K, follows the same line of Hayles' theory, to the extent that it tries to "put back into the picture the flesh that continues to be erased in contemporary discussions about cybernetic subjects" (Hayles 5, our emphasis).

We return, thus, to Zero $K$. The novel's narrative takes place in primarily two settings: on the island of Manhattan and within the Convergence facility. Although the first setting offers us the original perceptions about life in the postmodern city that we have come to expect from Don DeLillo, it is in the incredible setting of the Convergence that the author's obsession with death and technology find the perfect space to develop.

The Convergence is located in the middle of a desert near Kazakhstan and appears to have been born from a science fiction film. Built in this remote site for the purpose of isolation, "[m]inimal contact [...] [d]etachment [...] [d] isinfestation" (DeLillo 129), it serves as a refuge from society, culture, and history, guiding them in order to be "outside the limits [...] forgetting everything they knew" (DeLillo 31). Much of its structure lies underground, with "buildings in hiding, agoraphobically sealed" (DeLillo 4-5), hundreds of corridors and numbered levels, doors that lead to nowhere, elevators that move horizontally, simulated English gardens; in short, a "literal landmark of implausibility" 
(DeLillo 115).

Its habitable sections are made specifically to show no particularity or differentiation, devoid of colors other than gray and pastel, with no view to the outside, producing a labyrinthine skeleton populated by anonymous rooms, which are exemplified in Jeff's description of his temporary bedroom: "the room was small and featureless. It was generic to the point of being a thing with walls. The ceiling was low, the bed was bedlike, the chair was a chair. There were no windows." (DeLillo 20). Even the food was unidentifiable, "contain[ing] no clue [whether] the meal ... was breakfast or lunch" (DeLillo 89).

This lifeless arrangement often extends to the very individuals working in the compound. Most of the staff is completely nameless and act robotically, fulfilling nothing more than their designed functions, ignoring Jeff's several attempts at making conversation. This often compels Jeff to invent names and backgrounds for them, one recurring coping mechanism of the protagonist. However, given enough time devoid of meaningful interactions, wandering through its featureless rooms, eating their unidentifiable food, Jeff asserts how "[y]ou can forget your name in this place" (DeLillo 31). In fact, this seems to be one of the main goals and repercussions of the structure. The setting itself prompts an abandonment of characteristics and individualities.

The stifling effect of this environment is immediate in Jeff, who finds himself "absorbed in the essential content of the place" (DeLillo 21), feeling trapped amid the prohibition to leave the Convergence. This effect, as DeLillo describes, is further enhanced by the brain-dead state of his smartphone and the lack of internet access in any way, a certainly ironic nudge into the modern concept of freedom. Later, the protagonist correctly theorizes that this whole design is a deliberate attempt to transform the complex into an "introspective box" (DeLillo 89), and these are calculated contributions to the compound's planned isolation, in order to get individuals to concentrate exclusively on the Convergence ideas.

Of the many aspects worth discussing about the Convergence, perhaps the art exhibited in its labyrinthine halls stands as one of its most striking features. Specifically, the several mannequins scattered within and out of the compound, which often display features and gestures more human than the individuals encountered there, behaving as "sentinel[s], posing forbiddingly [...] their stillness [...] willed" (DeLillo 132). Laura Barret (2018) discusses how mannequins serve as an "introduction to the blurring of margins" (109) between flesh and plastic, human and artificial, between life and death. The author adds that "the tenuous distinction between humans and dolls is most chillingly illustrated in the use of bodies as art" (109), which often enter the domain of the bizarre. In a gallery that initially seems to be empty, Jeff and Ross encounter a "small human figure, motionless" (DeLillo 148), kept alive, altered chemically to be preserved in stillness - "one small body with a beating heart [...] a living breathing art form" (DeLillo 149). The most grotesque of the encounters with this "postmortem décor" (DeLillo 232) occurs in a corridor that exhibits several nude, headless figures. As one of the escorts announces, these are actual bodies, "not [...] 
replica[s] of silicone and fiberglass. Real flesh, human tissue, human being [...] preserved for a limited time by cryoprotectants applied to the skin" (DeLillo 231).

As it turns out, the lack of distinction in the treatment of plastic and human bodies in art form serves as just a prelude to the objectification of the body as an accessory, disposable and replaceable. As Hayles points out in her research,

the posthuman view thinks of the body as the original prosthesis we all learn to manipulate, so that extending or replacing the body with other prostheses becomes a continuation of a process that began before we were born. [...] [B]y these and other means, the posthuman view configures human being so that it can be seamlessly articulated with intelligent machines. In the posthuman, there are no essential differences or absolute demarcations between bodily existence and computer simulation, cybernetic mechanism and biological organism, robot teleology and human goals. (Hayles 3).

Hayles' concerns with disembodiment come alive in Zero K's pages through the art and ideology of the Convergence. Throughout the novel, the reader is somewhat left to speculate, as we are never given full disclosure of the future procedures. But we do know that the Convergence's plans involve a partial or complete erasure of body and flesh, as members of the compound speak of having "[p]arts of the body replaced or rebuilt", or sometimes, of a total "reassembling, atom by atom" (DeLillo 47). Even a new language, designed to deepen their intellect and expand reality, would be implanted in the subjects in cryopreservation.

In a way, both the bodies used as art in the halls and the bodies preserved in the cryonic pods are nothing more than pure spectacle. "[S]tripped of their essential organs" (DeLillo 140), these are essentially human mannequins for display, while their brains and, sometimes, entire heads, kept in different casings, await to be "grafted to a healthy nanobody" (DeLillo 147).

Finally, the art of the Convergence seems devoted to reflect an environment "[d]efined by stillness, both human and environmental", establishing a "tomblike" structure (DeLillo 10); all this composition designed to remind them continuously of death, and of their desire to escape from it or to overcome it at any cost. Or, and perhaps more precisely, to remind them that they are already dead, that the end is near - " $t]$ his was art that belongs to the afterlife. It was art that accompanies last things, simple, dreamlike and delirious. You're dead, it said" (DeLillo 119, our emphasis) - and the Convergence is the only answer.

For the directors, the belief that started the endeavor is that the whole of humanity is inevitably doomed, that the apocalypse is imminent. In fact, for them, it is already underway, and the main culprit, in one way or another, will be technology. In a form of propaganda that serves as an incessant reminder, the compound halls display huge screens continuously transmitting images of catastrophes incurred through war, terrorism, and climate change, all severely aggravated by technological advancement. The sheer size of the screens "lift[s ] the effect out of the category of TV news" (DeLillo 11). But more than that, as 
the scenes advance the images long past what is usually shown in mainstream media, they surround the viewer in excruciating detail of disease, death, mass destruction, biological warfare - with cameras often lingering on the bodies, on burning men with their mouths open, and so on.

Therefore, the Convergence compound would stand as a shield against the inevitable day when nations "begin to deploy the most hellish weapons" (DeLillo 241-242). This is not, however, their only concern regarding technological advancement. Under the surface of everyday use, the Convergence recognizes other, more insidious dangers of technology.

In speeches that approach brainwashing, discourses that sound to Jeff as some incantation, haunting a room (DeLillo 77), some of the head directors explain these perils:

"That world, the one above," she said, "is being lost to the systems. To the transparent networks that slowly occlude the flow of all those aspects of nature and character that distinguish humans from elevator buttons and doorbells. [...]

"Those of you who will return to the surface. Haven't you felt it? The loss of autonomy. The sense of being virtualized. The devices you use, the ones you carry everywhere, room to room, minute to minute, inescapably. Do you ever feel unfleshed? All the coded impulses you depend on to guide you. All the sensors in the room that are watching you, listening to you, tracking your habits, measuring your capabilities. All the linked data designed to incorporate you into the megadata. Is there something that makes you uneasy? Do you think about the technovirus, all systems down, global implosion? Or is it more personal? Do you feel steeped in some horrific digital panic that's everywhere and nowhere?" (DeLillo 239, our emphasis).

Although Jeff is adamantly resistant to most of the ideas presented by the Convergence, he too feels the depersonalizing effects of the "puppet drug of personal technology" (DeLillo 55, our emphasis), seeing himself "moving autonomically into middle age, an involuntary man" (DeLillo 193, our emphasis).

DeLillo refers to this era of maximum technological stimulation as the "scatterlife". Its narcotic pull provides cheap entertainment and extreme convenience, but at the cost of having no "firm placement [in the] world" (DeLillo 271). In Zero K's running joke involving ATMs, Jeff examines several of his withdrawal receipts, and discovers a series of constant errors in his balance. Some small amounts of money end up missing every day. The convenience of the touch-screen life and immersion in the virtual world has hidden costs. They may seem trivial at first, but they add up daily.

Furthermore, the speech above suggests that there is more to technology's pervasive influence than addiction and total distraction. There is also the sense of being watched, monitored, tracked, all of it to keep your behavior normalized, and, most importantly, to transform you into quantifiable data. Not "who", but "how many" and "how much". It is safe to say many people have felt the pressures of work, of all "the sensors" used to track what you've been doing on your 
computer, all the while "measuring your capabilities" - How many calls did you make? How many clients did you bring? How much did you sell? How many articles have you published? So on and so forth. Even in social media, "success" is usually determined by numbers, by the amount of "likes" your post has accrued, or the amount of followers you have gathered on Twitter or Instagram. Social media is also especially useful for the tracking of habits and the design of targeted propaganda. "All the linked data designed to incorporate you into the megadata" (DeLillo 239, our emphasis). Technology makes it easy to reduce a person to numbers and percentages in a profile.

Subjectivity being reduced to a set of specific information is not at all a strange topic in DeLillo's novels. Apart from Zero K, perhaps the most prominent of his works that deals with this subject is Underworld (1997). The novel is famous for showing different perspectives in its reevaluation of historical facts during the Cold War period. As such, it portrays the subverted character of J. Edgar Hoover, the powerful Director of the FBI, in his ability to manipulate information through dossiers in order to fabricate identities for individuals and even create History itself.

The range of the director's pervasive power is felt in the scene portraying the baseball game held at the stadium, in which Hoover appears alongside important figures, such as Frank Sinatra, Jackie Gleason and Toots Shor. Even their status does not make them immune to "the nation's number one G-man", owner of people's private lives through the FBI files:

What's the nation's number one G-man doing with these crumburns? [...] He likes to be around movie idols and celebrity athletes [...]. Fame and secrecy are the high and low ends of the same fascination [...]. He wants to be their dearly devoted friend provided their hidden lives are in his private files, all the rumors collected and indexed, the shadow facts made real. (DeLillo 17).

"[T] he shadow facts made real" certify how powerful Hoover's files were when it came to affecting subjects. Revealing an upsetting truth, the novel makes it clear that it was not relevant if the information contained in them was mostly rumors. In "The Power of History”, DeLillo posed the question “[d]oesn't a fiction writer necessarily distort the lives of real people?” (62). Hoover's bureaucratic routine provides a dark example of this scenario, in which the character altered genuine lives through fabricated information. In the hands of the powerful director, once it was collected and indexed in the files, fiction was made real.

Hoover's way of acting in Underworld is mainly through the dossiers, a powerful device exploited in order to gain control of individuals:

In the endless estuarial mingling of paranoia and control, the dossier was an essential device. Edgar had many enemies-for-life and the way to deal with such people was to compile massive dossiers. Photographs, surveillance reports, detailed allegations, linked names, transcribed tapes-wiretaps, bugs, break-ins. The dossier was a deeper form of truth, transcending facts and actuality. The second you placed an item in the 
file, a fuzzy photograph, an unfounded rumor, it became promiscuously true. It was a truth without authority and therefore incontestable. Factoids seeped out of the file and crept across the horizon, consuming bodies and minds. The file was everything, the life nothing. And this was the essence of Edgar's revenge. He rearranged the lives of his enemies, their conversations, their relationships, their very memories, and he made these people answerable to the details of his creation. (DeLillo 559).

Hoover reshaped facts and subverted them, rearranging experiences and identities. Gathered in the official form of the dossiers, the details of their content became unquestionable truths. The character Tanya Berenger, for example, "was in the files in a fairly big way. She'd been accused at various times of being a lesbian, a socialist, a communist, a dope addict, a divorcee, a Jew, a Catholic, a Negro, an immigrant and an unwed mother" (DeLillo 561). The Director "worked in the semidark, manipulating and bringing ruin" (DeLillo 570-571) in order to make subjects answerable to the archives he had elaborated. The documents became legitimate when the subversions met the Director's expectations and desires, and as such, the dossiers effectively corresponded to a reinvention of those people's lives and an efficient form of control.

It is arguable that technological advancement has made the above fears even more real in the present context. Surveillance is spreading exponentially, and so are the means to fabricate and disperse information throughout the world. A compromising picture or statement, real or not, widely circulated through the web, is enough to destroy a person's life.

Interpreting brilliantly the spirit of his time, Delillo brings to light a frightening world of uncertainties, in which we are helplessly unable to control the new narratives that are being created through modern technological devices.

Back to Zero $K$, after analyzing the possibility of imminent destruction and other dangerous effects of technology, the Convergence reaches the conclusion that "[ $t$ ]echnology has become a force of nature" (DeLillo 245) which cannot be controlled, except, of course, right there, in that location. In a way, the Convergence is supposed to function as a refuge from technology, from "[a]ll the voice commands and hyper-connections that allow you to become disembodied" (DeLillo 127, our emphasis).

But the incredible irony of this speech is not lost on the reader. How can this be the path? How can this lifeless compound be the home of human rebirth? How is employing billions of resources in this capacity saving humans in any way? Not only do they depend on technology itself to engineer their escape, but they also seem to be accelerating exactly what they set out to avoid. They express fear of becoming unfleshed, disembodied, and virtualized, but give themselves over to be torn apart, their bodies perversely treated as "toys to [be] play[ed] with" (DeLillo 72, our emphasis), becoming, in the process, nothing more than "clinical specimens" (DeLillo 47).

In the vain pursuit of immortality as a form of salvation sold by the complex, they surrender the flesh that holds, at least partially, the very thing they hoped to preserve - their own humanity. 
However, to the Convergence supporters, there are also dreams of meeting your true self through profound introspection while in the cryonic pod: "[w]e are pledged to an inwardness, a deep probing focus on who and where we are $[\ldots]$ [y] ou are about to become, each of you, a single life in touch only with yourself" (DeLillo 237), says one of the leaders.

As an unsettling representation of what the Convergence endeavor actually achieves in trying to disregard the body and the world, connecting exclusively with the mind, we are given access to Artis' faint consciousness in the pod, continuously engaged in a monologue that alternates between the first and the third person:

\author{
But am I who I was. \\ I hear words that are saying things to me again and again. Same words all \\ the time going away and coming back. \\ Am I someone or is it just the words themselves that make me think I'm \\ someone. \\ Why can't I know more. Why just this and nothing else. Or do I need to \\ wait. \\ Are the words themselves all there is. Am I just the words. \\ Does it keep going on like this. \\ Where am I. What is a place. \\ Why can't I know more. Why just this and nothing else. Or do I need to \\ wait. \\ Are the words themselves all there is. Am I just the words. \\ She is the residue, all that is left of an identity. \\ I am only what is here and now. \\ Is this the nightmare of self drawn so tight that she is trapped forever. \\ I think I am someone. What does it mean to be who I am. \\ I try to see the words. Same words all the time. \\ I think I am someone. But I am only saying words. \\ But am I who I was. \\ On and on. (DeLillo 157-162, emphasis on the original).
}

Separated from her body, Artis questions herself repeatedly - "Am I who I was"? "Why just this and nothing else"? "Am I just the words"? Her state seems to confirm Robert Pepperell's observations in The Posthuman Condition (2003), in which he affirms that consciousness and intelligence go beyond the brain. Interestingly, among the author's many arguments supporting his claim, one of them is a research done by McGill University about the "damaging effect upon human consciousness of sensory deprivation; that is, when the brain is left entirely to itself in the absence of bodily stimulation" - a description which closely recalls Artis' condition in the cryonic pod. Their findings show that in cases like this, "the normal functioning of the mind breaks down, with an onset of hallucination and eventual severe trauma. Without the continuous flow of varied information it is used to receiving from the body and the world the mind cannot operate properly" (Pepperell 18).

Unable to receive any sensory stimuli and having seemingly no memory, Artis functions, ironically, as a malfunctioning machine, trapped indefinitely in 
a cycle of feedback loops that yield no results. As it stands, this experience is not the deep introspection and revelation of the true self they hoped for, but a total disconnection with the rest of oneself, other people, and the material world binding us. Borrowing the cleverly adapted words of Nathaniel Rich's review (2016), "[h]ell is the absence of other people".

Compelled by the desire to take death under control, swollen fantasies of an extraordinary transcendence, and fears of the apocalypse, Artis, Ross and hundreds of others find only an incomplete, disembodied and disconnected existence in the chilling halls of the Convergence.

As Hayles reminds us, "the posthuman does not really mean the end of humanity. What is lethal is not the posthuman as such but the grafting of posthuman onto a liberal humanist view of the self" $(286,287)$.

Just as disembodiment is not the answer to issues of mortality, neither is the abandonment of the present world alongside the full trust in technology to bail us out from extinction. Glavanakova concludes that DeLillo's Zero K ultimately reveals how "investing technology with the hope that it will supply a permanent solution to the problem of mortality is both delusional and a dangerous distraction from the very real problems of the Age of Humans" (106).

It is in light of this type of dangerous behavior and philosophy, that Katherine Hayles writes her aforementioned book as a form of intervention, aiming to steer posthuman thought in a different direction:

If my nightmare is a culture inhabited by posthumans who regard their bodies as fashion accessories rather than the ground of being, my dream is a version of the posthuman that embraces the possibilities of information technologies without being seduced by fantasies of unlimited power and disembodied immortality, that recognizes and celebrates finitude as a condition of human being, and that understands human life is embedded in a material world of great complexity, one on which we depend for our continued survival. (Hayles 5, our emphasis).

It is therefore critical that we contest what the posthuman means, and that we do it now, in order to keep disembodiment from, once again, being written into prevailing concepts of subjectivity. Notwithstanding the challenges ahead, the posthuman has to recognize that our fate is inextricably intertwined to that of the world, and that we depend on a balanced reconciliation of existence not only to thrive, but to survive: "[t]o harm anything is to harm oneself" (Peperell 172).

In the last chapter of Zero K, after all is said and done, we are left with Jeffrey, the so-labeled skeptical and noncommittal for rejecting the Convergence's propositions. It is certainly true that, like so many DeLillo characters, Jeffrey is unsure of who he is, displaying a tendency of "drift[ing] into things", moving from job to job, city to city, girlfriend to girlfriend, in a refusal to settle. By the novel's end, however, Jeffrey seems like the only character who actually evolves in contrast to the ones that abide by the ideals of the Convergence. He does not need an "introspective box" or shrine for self-examination. We find him simply 
walking the streets, trying to cope with the "death" of his father and stepmother, "feeling an immanence, the way in which a painful loss yields a shadow presence" (DeLillo 266), and reflecting on his relationship with his last girlfriend Emma, and "his damning failure to tell her who [he] was" (DeLillo 271) - in short, accepting that loss and regret are part of the experience of being human. Most importantly, we find him living in the world and paying more attention to the wonders of the everyday, finding transcendence in the ordinary. In the last scene of the novel, Jeffrey witnesses the Manhattanhenge, both a natural and manmade phenomenon, when the "sun's rays align with the local street grid". He listens to a very young boy wailing and uttering "prelinguistic grunts", acknowledging that they are "far more suitable than words", and finally moves closer to him to better experience his "cries of wonder" (DeLillo 273-274). In just one scene, DeLillo encapsulates the posthuman in connection with manmade structures brought by our technology, with the marvels of nature as well the wonders of human interaction. In clear opposition to the lifeless arrangement of the Convergence, it is only Jeff who remains human in any capacity of the word, embracing the sufferings, pleasures, and limits of his human condition.

\section{References}

Barrett, Laura. "[R]adiance in dailiness": The Uncanny Ordinary in Don DeLillo's Zero K. Journal of Modern Literature, 42(1), p. 106-123, 2018, https://www.jstor. org/stable/10.2979/jmodelite.42.issue-1. Accessed September 2018.

Costa, Claudia de Lima; Cavalvanti, Ildney de Fátima Souza; HARAN, Joan. On the Posthuman. Itha do Desterro, v. 70, n. 2, p. 9-14, 2017.

DeLillo, Don. Cosmopolis. New York: Scribner, 2003.

"The Power of History". The New York Times Magazine, September 7, 1997, p. 60-63.

Underworld. New York: Scribner, 1997.

Zero K. E-book. Canada: Scribner, 2016.

Ferrando, Francesca. Posthumanism, Transhumanism, Antihumanism, Metahumanism, and New Materialisms: Differences and Relations. Existenz, v. 8, n. 2, p. 26-32, 2013.

Glavanakova, Alexandra K. The Age of Humans Meets Posthumanism: Reflections on Don DeLillo's Zero K. Studies in the Literary Imagination, v. 50, n. 1, p. 91-109, 2017.

Haraway, Donna. A Cyborg Manifesto: science, technology and socialist-feminism in the late twentieth century. University of Minnesota Press, 2016, https:// warwick.ac.uk/fac/arts/english/currentstudents/undergraduate/modules/ fictionnownarrativemediaandtheoryinthe21stcentury/manifestly_haraway_---_a_cyborg_manifesto_science_technology_and_socialist-feminism_in_the_... pdf. Accessed January 2020. (First published 1985)

Hayles, N. Katherine. How We Became Posthuman: Virtual Bodies in Cybernetics, Literature and Informatics. Chicago; London: The University of Chicago Press, 1999.

Moravec, Hans. Mind Children: The Future of Robot and Human Intelligence. Cambridge: Halvard University Press, 1988. 
Pepperell, Robert. The Posthuman Condition: consciousness beyond the brain. Bristol, UK: Intellect Books, 2003.

Rich, Nathaniel. "When High Technology Meets Immortality". The New York Times, New York, 9 Jun. 2016, https://www.nybooks.com/articles/2016/06/09/dondelillo-when-high-technology-meets-immortality/. Accessed September 2018.

Recebido em: 19/06/2020

Aceito em: 27/08/2020 